\title{
(十) A CASE REPORT: FUNCTIONING CYSTIC PHEOCROMOCYTOMA
}

\author{
Boysan S Nur ${ }^{1}$, Kokdas Suleyman², Gungor Tuba ${ }^{3}$, Citil Rana ${ }^{4}$, \\ Citil Serdal' ${ }^{5}$, Dagoglu Besra ${ }^{5}$, Caglar Serkan ${ }^{6}$ \\ 1 Department of Endocrinology, ${ }^{2}$ Department of General Surgery, ${ }^{3}$ Department of Anesthesiology, \\ ${ }^{4}$ Department of Pathology, ${ }^{5}$ Department of Radiology, ${ }^{6}$ Department of Biochemistry
}

\section{Kahramanmaras Necip Fazil City Hospital}

\section{Introduction}

- $\quad$ Cystic adrenal neoplasms are uncommon; defined with foci of tumor presented in the cyst wall.

- $\quad$ Adrenal cortical adenoma, adrenal cortical carcinoma and pheocromocytoma may be associated.

- $\quad$ Abdominal pain, gastrointestinal symptoms and a palpable mass are the most emerging complaints.

- We report a case of functioning cystic pheocromocytoma.

\section{Case Report}

Medical history

- A 44-year-old man had an abdominal pain on the right side.

- He had a mild hypertension.

Radiology

- Abdominal ultrasonography showed a nodular cystic lesion measured $4 \mathrm{~cm}$ in diameter with thin septas and thickened wall in the right adrenal.

- $\quad$ Computed tomography confirmed hypodense lesion measured as $78 \times 48 \mathrm{~mm}$ in diameter and $40 \mathrm{HU}$ in density (Figure 1A).

- Magnetic resonance imaging demonstrated nonsuppressed lesion in fat-suppressed sequence (Figure 1B).

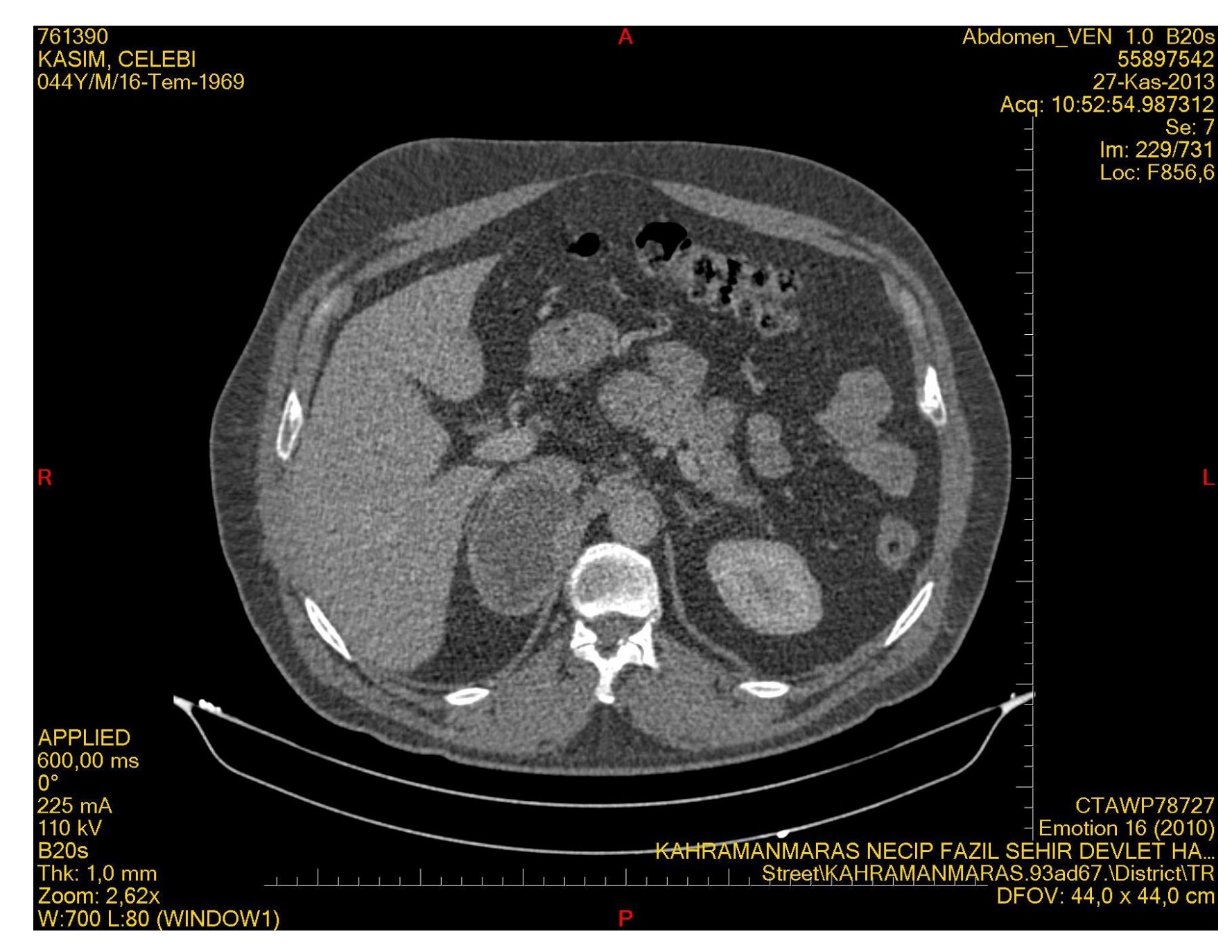

Figure 1A

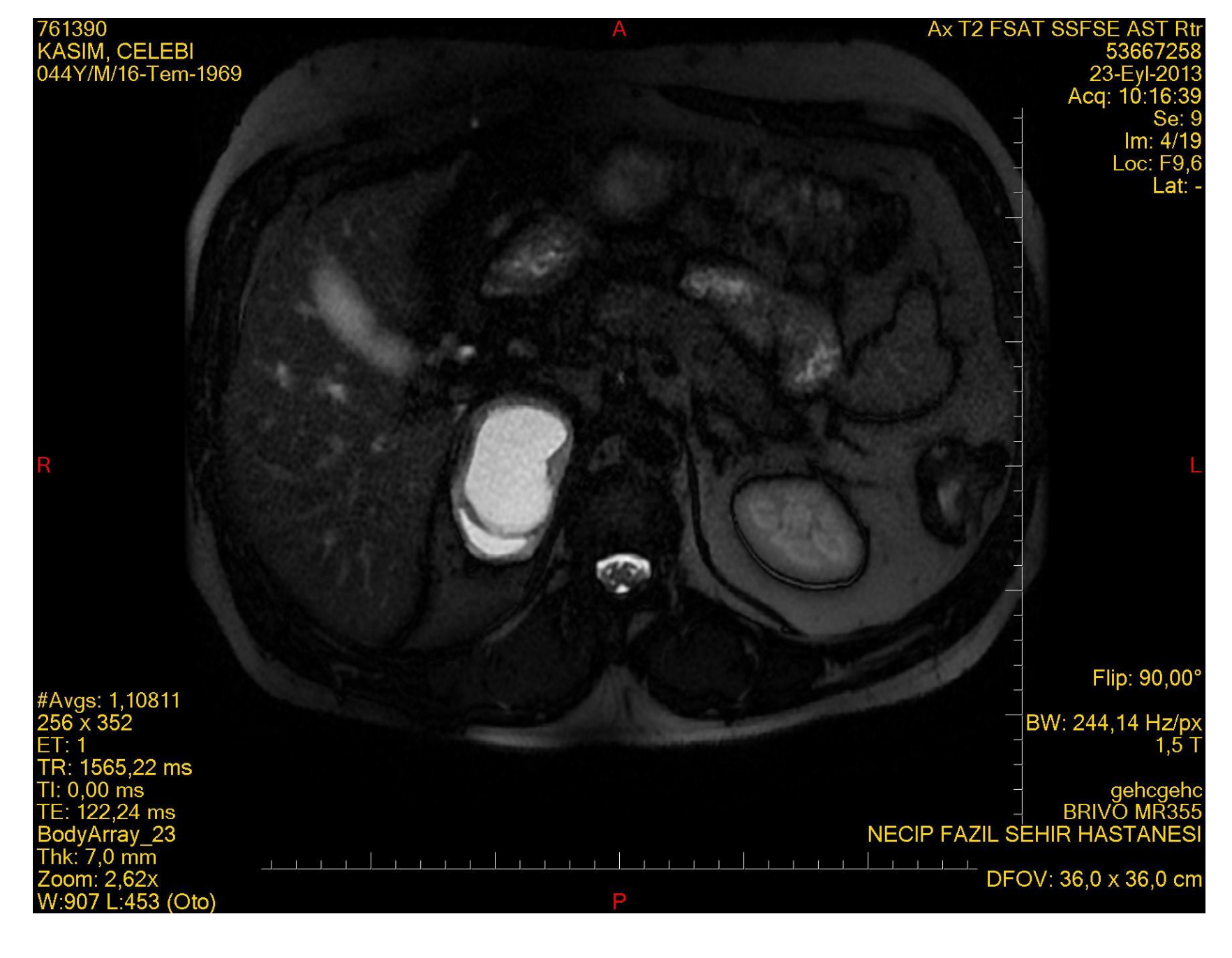

Figure 1B
Laboratory

$\mathrm{ACTH}$

Cortisol

Urine cortisol

$1 \mathrm{mg}$ Dex. Sup.

Plasma Renin Activity

Aldosterone

VMA

Urine metanephrines

Urine normetanephrines

Nuclear Medicine

\section{Preoperative management}

- $\quad$ Amlodipin and doxazosin were begun before 2 weeks

- Hydration was begun before 3 days.

Operation

- He underwent right adrenalectomy with minimal invasivelaparoscopic surgery (Figure 2).

- $\quad$ Anesthetic induction was performed with fentanyl, propofol, vecuronium and lidocaine.

- During manuplation of adrenal lesion three hypertensive attacks occured; infusion of nitroglycerine, nitroprusside and diltiazem were given.

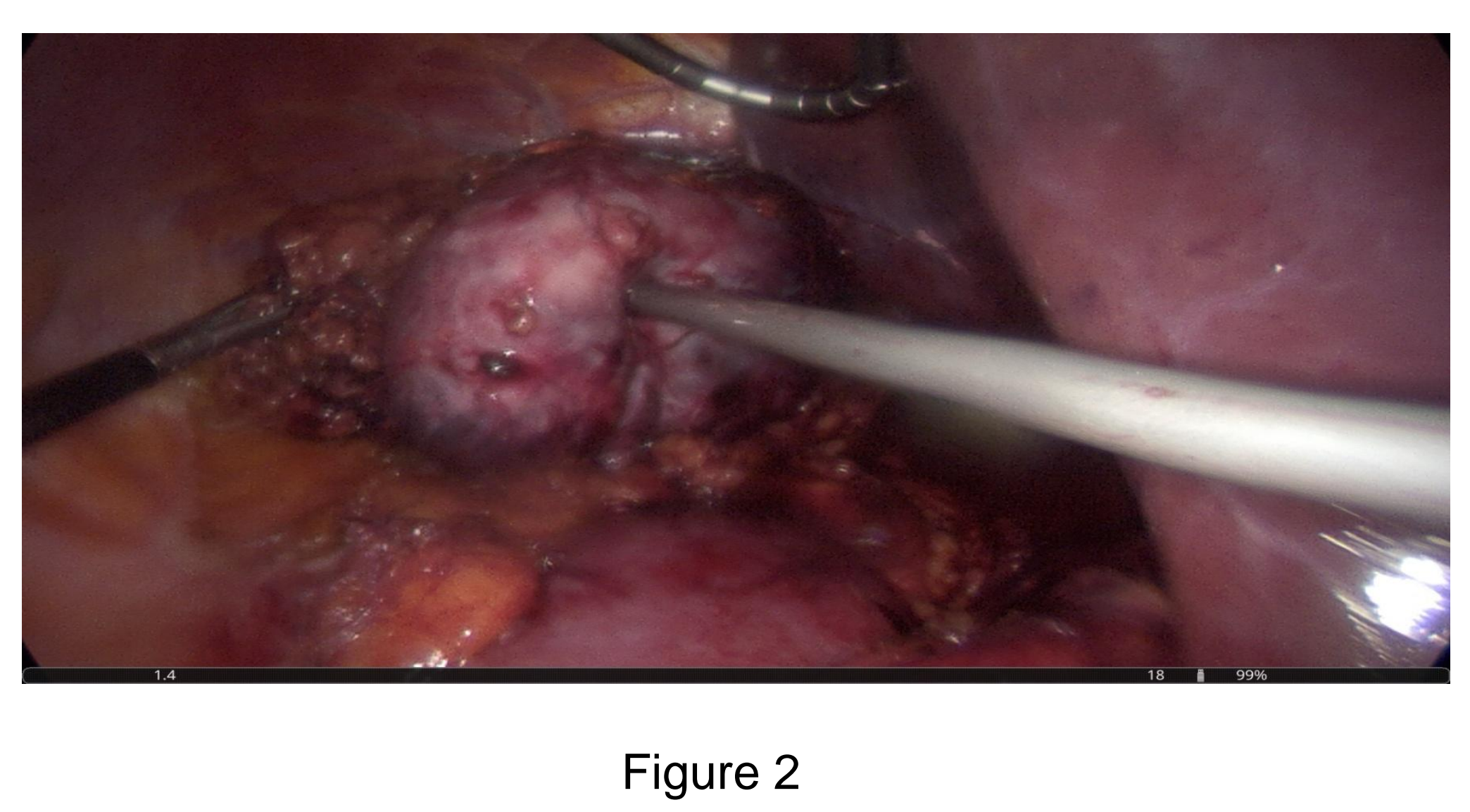

Pathology

- $\quad$ Cystic strucrure with fibrotic wall; surrounded with solid areas of thinny septas and alveolar tumoral tissue (Figure $3 A-B)$.

- Tumoral tissue was diffuse and strongly staining with chromogranin -A (Figure 3C).

Ki-67 staining was $0.1 \%$.

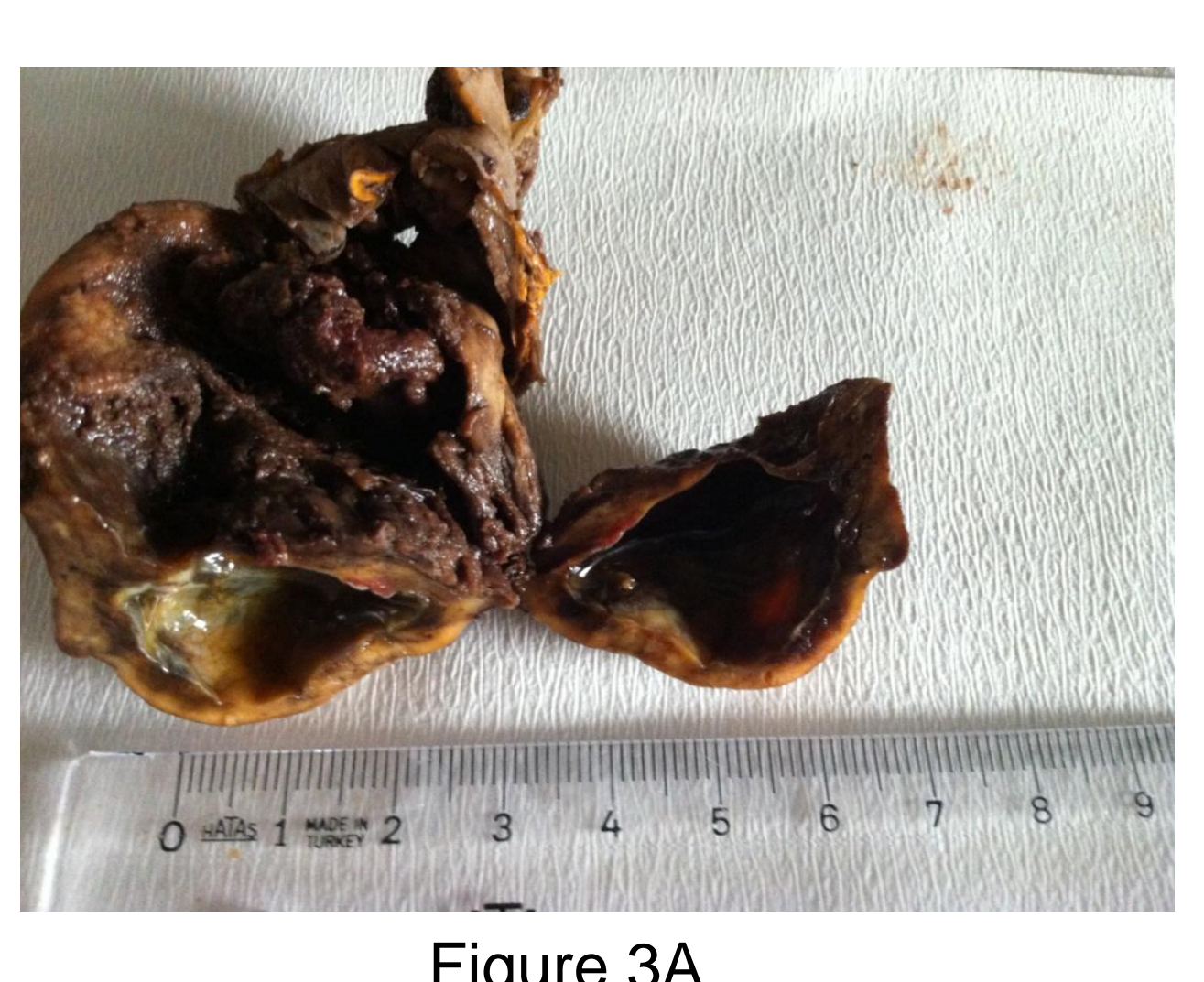

Figure $3 \mathrm{~A}$

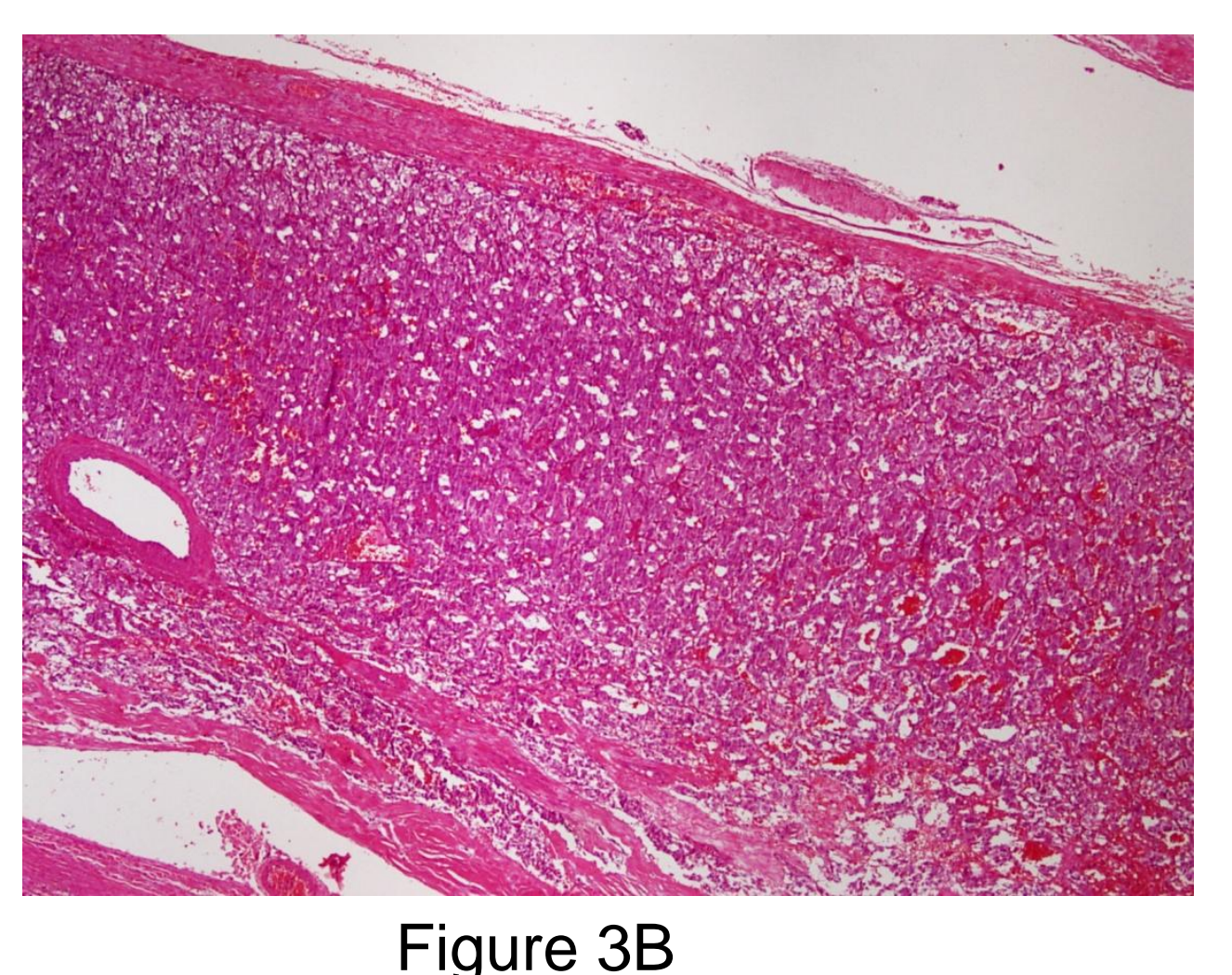

Figure 3B

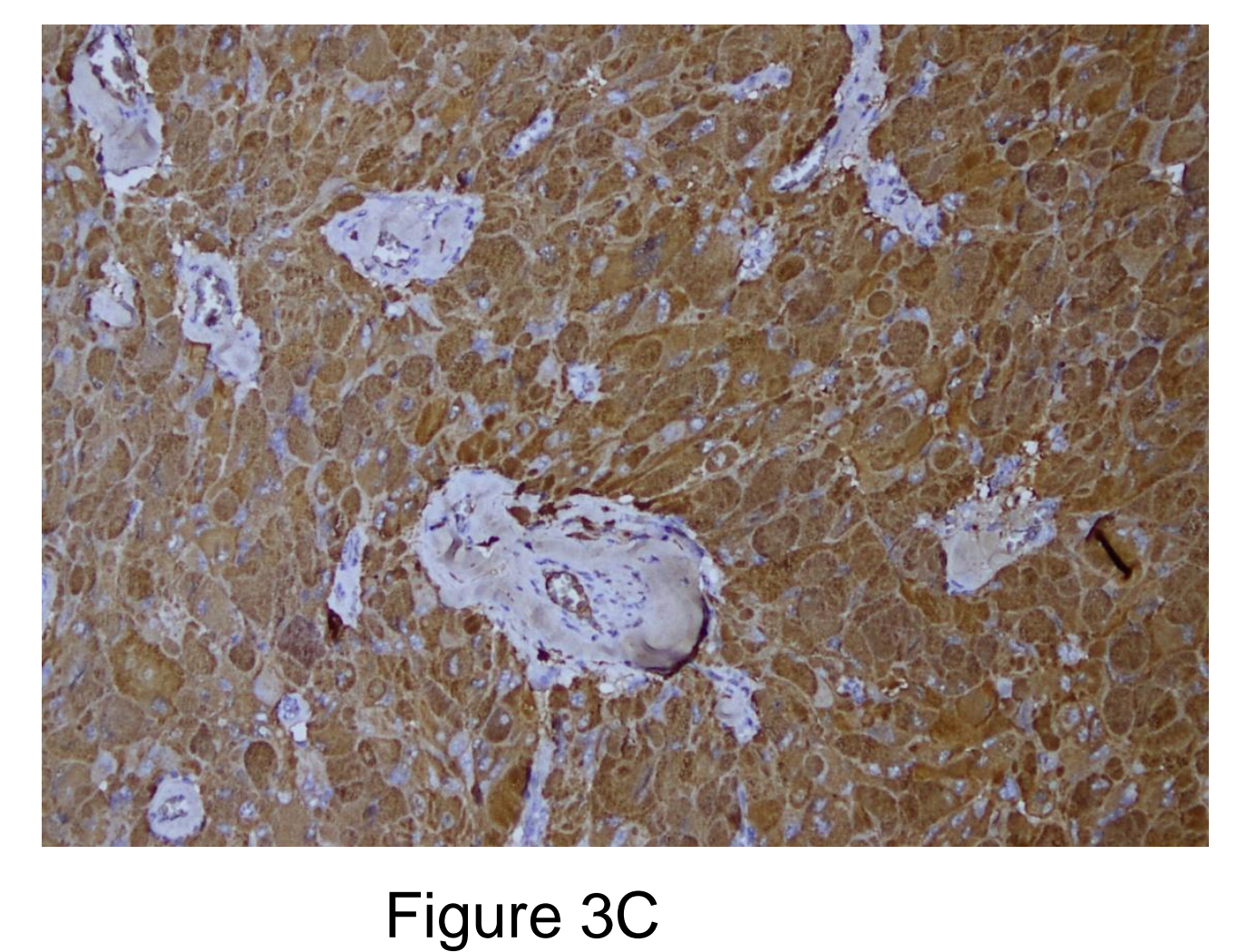

Figure 3C
Clinical course

- $\quad$ Postoperative he was normotensive.

\section{Conclusion}

$\mu \mathrm{g} / \mathrm{dL}$

$\mu \mathrm{g} / \mathrm{day}$

$\mu \mathrm{g} / \mathrm{dL}$ $\mathrm{ng} / \mathrm{mL} /$ hour $\mathrm{ng} / \mathrm{dL}$ $\mathrm{mg} /$ day $\mu g /$ day $\mu \mathrm{g} /$ day
- $\quad$ lodine-123 MIBG images showed right adrenal lesion accumulation
Adrenal cysts may be incidental or symptomatic.

Pseudocysts, endothelial cysts, epithelial cysts and parasitic cysts are defined.

The explanation for the cystic change was marked haemorrhage or degeneration ; must be distinguished from tumoral necrosis.

- We report a case of cystic pheocromocytoma who was symptomatic and biochemically functioning. 